\title{
Review Article \\ The Wide and Complex Field of NAFLD Biomarker Research: Trends
}

\author{
Erika Wichro, ${ }^{1}$ Tanja Macheiner, ${ }^{1}$ Jasmin Schmid, $^{2}$ Barbara Kavsek, ${ }^{2}$ and Karine Sargsyan ${ }^{1}$ \\ ${ }^{1}$ BioPersMed/Biobank Graz, Medical University of Graz, Stiftingtalstrasse 3.1, Graz, 8010 Styria, Austria \\ ${ }^{2}$ Siemens AG Austria, Corporate Technology, Biosensors, Strassganger Strasse 315, Graz, 8045 Styria, Austria
}

Correspondence should be addressed to Karine Sargsyan; karine.sargsyan@medunigraz.at

Received 6 January 2014; Accepted 19 February 2014; Published 28 April 2014

Academic Editors: N. Mendez-Sanchez, L. Miele, and M.-L. Yu

Copyright (C) 2014 Erika Wichro et al. This is an open access article distributed under the Creative Commons Attribution License, which permits unrestricted use, distribution, and reproduction in any medium, provided the original work is properly cited.

Background. Nonalcoholic fatty liver disease is now acknowledged as a complex public health issue linked to sedentary lifestyle, obesity, and related disorders like type 2 diabetes and metabolic syndrome. Aims. We aimed to retrieve its trends out of the huge amount of published data. Therefore, we conducted an extensive literature search to identify possible biomarker and/or biomarker combinations by retrospectively assessing and evaluating common and novel biomarkers to predict progression and prognosis of obesity related liver diseases. Methodology. We analyzed finally 62 articles accounting for 157 cohorts and 45,288 subjects. Results. Despite the various approaches, most cohorts were considerably small and rarely comparable. Also, we found that the same standard parameters were measured rather than novel biomarkers. Diagnostics approaches appeared incomparable. Conclusions. Further collaborative investigations on harmonizing ways of data acquisition and identifying such biomarkers for clinical use are necessary to yield sufficient significant results of potential biomarkers.

\section{Introduction}

Nonalcoholic fatty liver disease (NAFLD) is acknowledged as a (public) health issue with an estimated prevalence of $30 \%$ in adults [1], of which approximately $25 \%$ progresses to nonalcoholic steatohepatitis (NASH) [2]. Sedentary lifestyle and high-fat and high-caloric dietary intake are strongly associated with NAFLD and nonalcoholic steatohepatitis (NASH). NAFLD and NASH occur not only in adults but also increasingly in childhood [3-5], accounting for a tremendous economic health burden [6].

The pathways of NAFLD/NASH and their alcoholinduced counterpart diseases are multifactorial, involving the liver metabolism key players: cytokines, adipokines, and apoptosis [7]. Alternative tools such as ultrasound or magnetic resonance imaging (MRI) [8] are becoming common in clinical routine; anyway in NAFLD/NASH diagnostics liver biopsy still remains the golden standard $[9,10]$.

In the context of personalized medicine, the research on biomarker to identify NAFLD and its development and progression is high priority for clinical routine. Our systematic data analysis of NAFLD research conducted in the last year, based on evaluation of extensive literature search, provided an overview of the most commonly published potential biomarkers for NAFLD.

\section{Methodology}

We performed an extensive literature assessment to evaluate known and novel biomarkers for progression and prognosis of NASH/NAFLD. In this context, we extracted and evaluated cohorts and parameters and consolidated scientific findings from the literature. We limited our keywords to "NAFLD OR NASH, 2010, 2011," accounting for a total of 1,833 articles, 1,517 articles from PubMed and 316 articles from ISI web of knowledge (Figure 1).

Cohorts meeting the selection criteria were included:

(i) english language;

(ii) human subjects;

(iii) adults;

(iv) cohort size $>60$ subjects;

(v) sufficient and reliable data; 


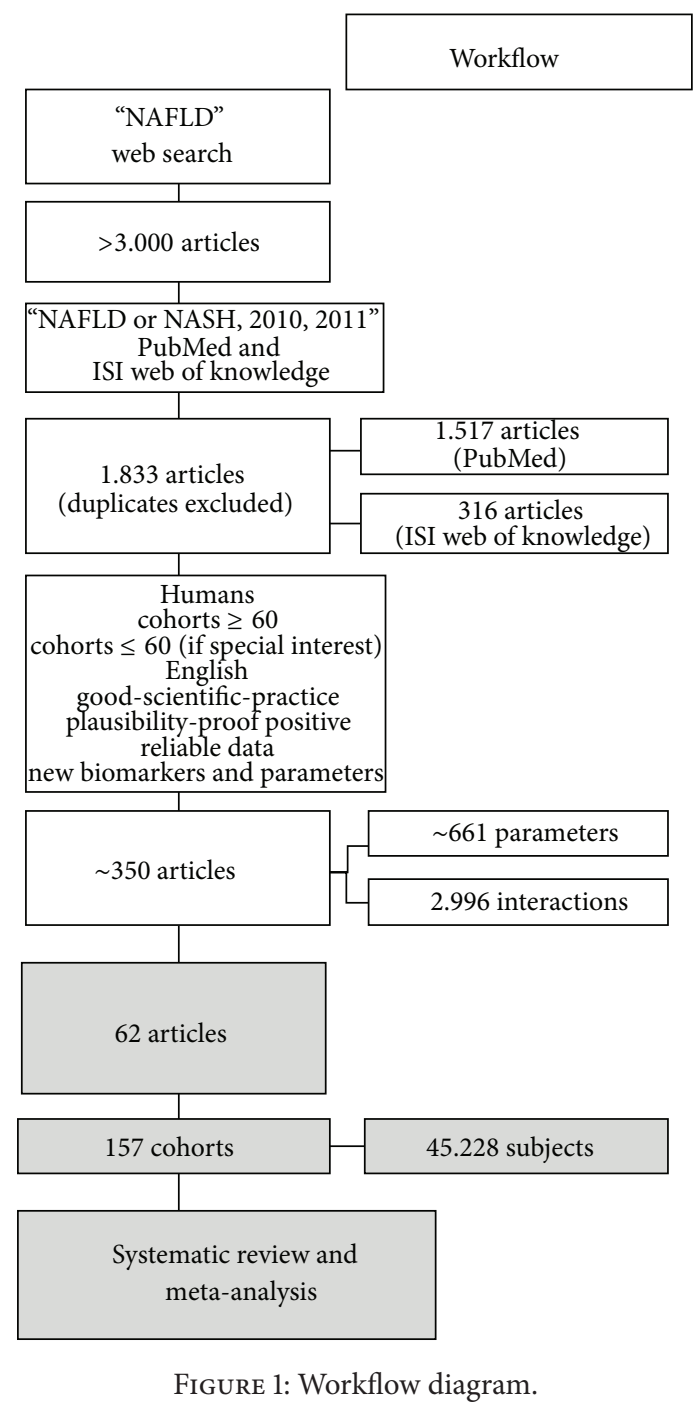

(vi) good scientific practice;

(vii) positive plausibility proof;

(viii) balanced grouping;

(ix) proven diagnosis (was not performed by an invasive liver biopsy at all studies).

Those cohorts not meeting the criteria were nevertheless scanned for potential parameters. Studies with cohorts below 60 subjects and presenting rare parameters such as potential biomarkers (e.g., ferritin, adiponectin, or rarely documented diabetic probands of NAFLD studies) and meeting all other criteria were included.

We transferred the cohorts of included studies in our subtypes' classification according to the definitions listed in Table 1.

\section{Statistical Evaluation}

Data-analysis approach is based on several requirements including studies with paired controls and balanced cohort size. The plots require an identical statistical summary measure, which means either using only the mean or only the median and requires the standard deviation known to derive confidence intervals. The information on deviations ranges or standard deviations (SD) proved not to be useful for further analysis and was omitted. To analyze a larger set of publications and to overcome limits of balanced cohort size, we included studies that had no paired control and pooled cohorts in several studies to ensure a comparable set.

The extracted mean values are displayed in boxplots by exploratory data analysis (EDA) and show median and 25 and 75 percentiles [11]. Mann-Whitney test was applied to compare the values between diseased and control groups; Kruskal-Wallis test was used to compare subjects of more than two groups. Statistical analysis was performed in $\mathrm{R}$ version 2.13.1 ( $\mathrm{R}$ Foundation for Statistical Computing, Vienna, Austria). $P$ values $<0.05$ were considered statistically significant.

Though a graphical representation of a small number of observations can be performed, a correct analysis is not possible. Therefore, statistical interpretation of results was performed particularly cautiously in such cases.

Finally, we used boxplots to visualize the measurements in arithmetic mean and the comparison between disease and relevant control groups.

\section{Results and Discussion}

4.1. Results. Based on the inclusion criteria, we comprised 62 studies, accounting for 157 cohorts and 45,228 subjects. Overall, we evaluated 81 different parameters provided in the included studies. Additionally, we bridged lifestyle and biomarkers by also including anthropometric values. Including gender was impossible because most studies showed no gender separation, but fulfilled all required criteria.

The noteworthy results are summarized in Figures 2, 3, 4 , and 5. The 62 included studies are listed in Table 2 and depicted results of different parameters given in arithmetic mean $(75.8 \%)$, in median (11.3\%) or mixed in mean and median (12.8\%).

In our scope of evaluation, we focused on the analysis of (1) available data, (2) significant results, and (3) potential use of parameters.

Our data analysis considered conventional parameters such as BMI, age, and systolic and diastolic blood pressure (Figure 2).

The BMI results of the healthy control group (1) were significantly lower than those of different disease groups, whereby the BMI appeared also significantly lower in (1) control group than in the related NAFLD-NASH group $(P$ value: $7.8 \times 10^{-12}$ ). Likewise, a significant BMI difference occurred between the diabetic group (3) and its control group ( $P$ value: $\left.1.48 \times 10^{-3}\right)$.

The results of age showed that the subjects of the (1) NAFLD-NASH group $\left(P\right.$ value: $\left.4.6 \times 10^{-3}\right)$ and similarly of the (3) DM group $\left(P\right.$ value: $\left.2.1 \times 10^{-3}\right)$ were significantly older in comparison to their control groups. 


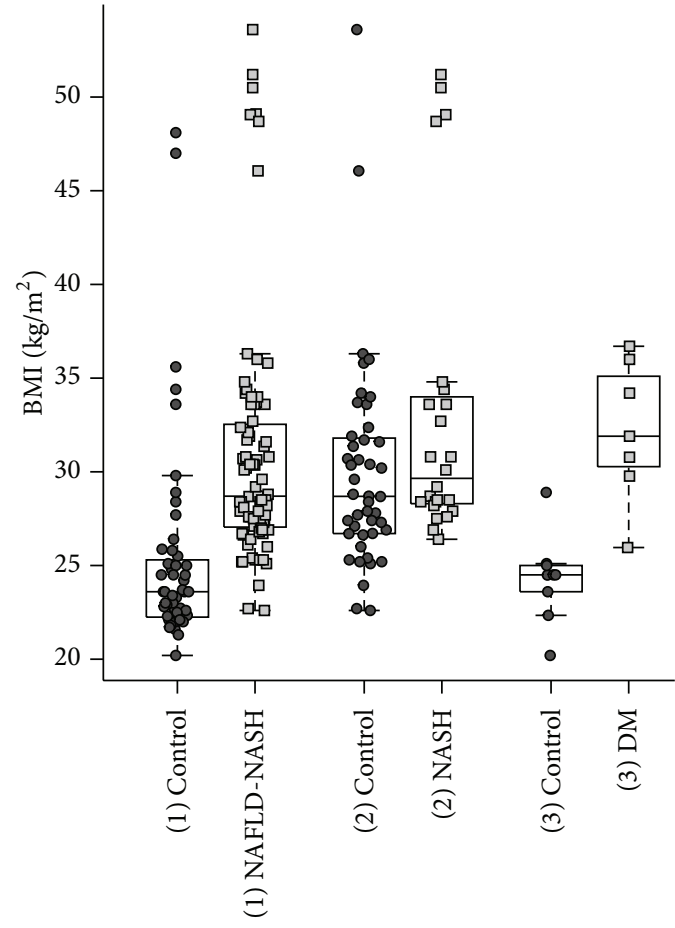

(a)

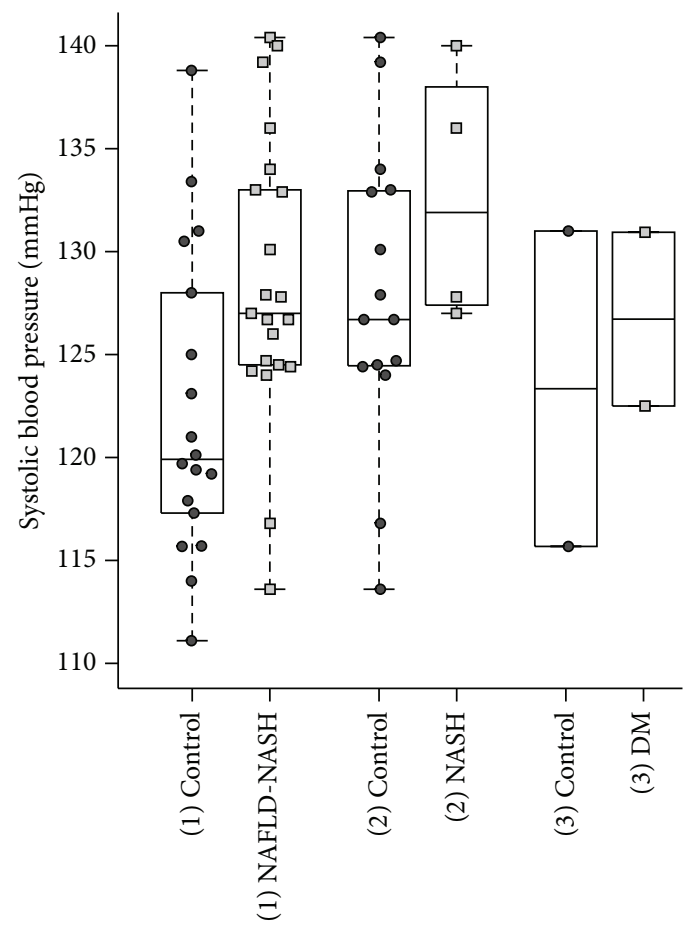

(c)

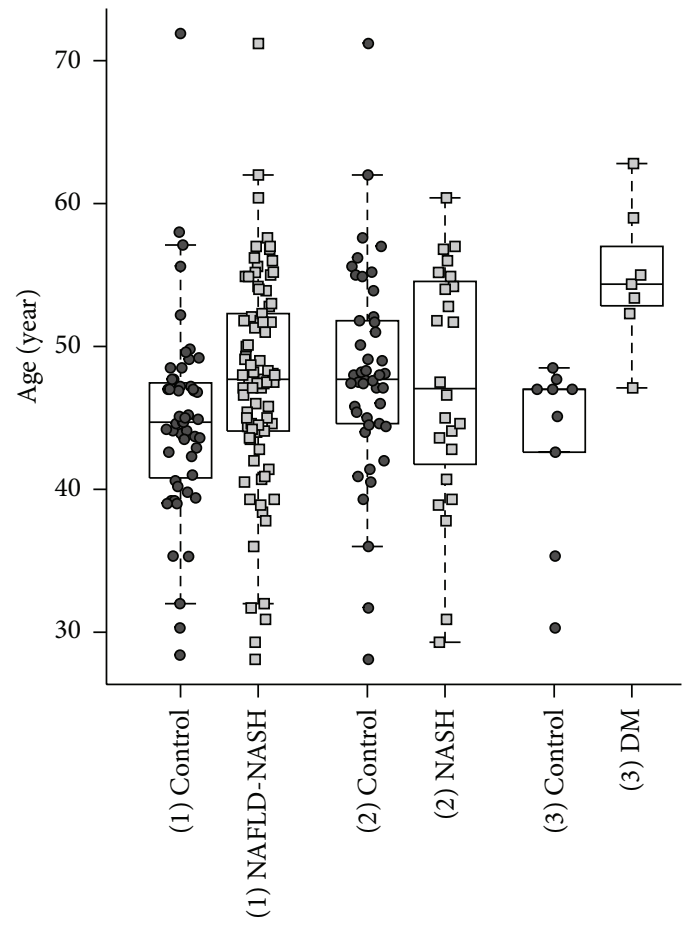

(b)

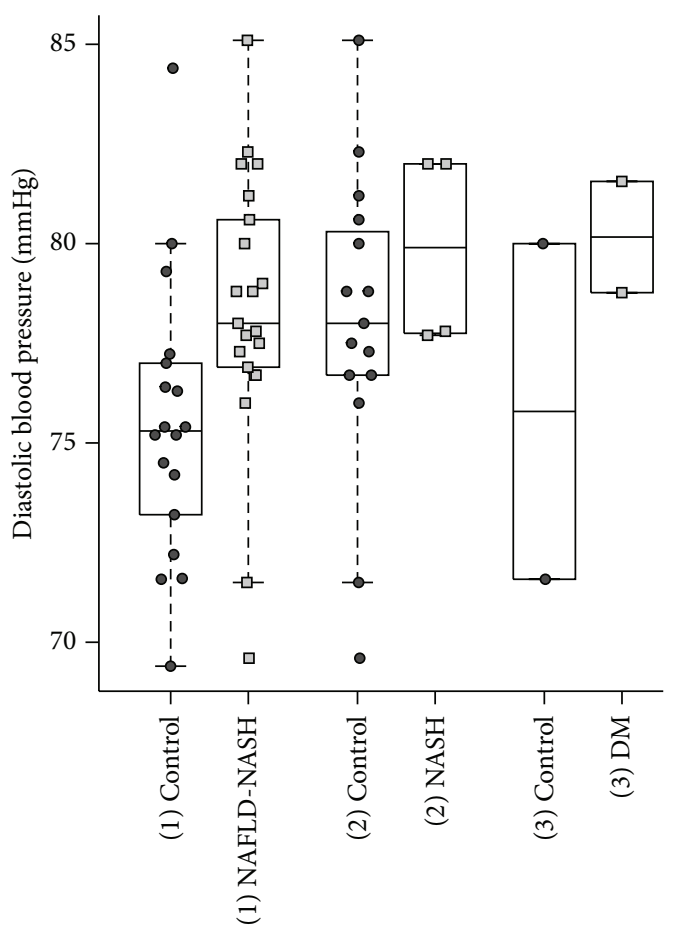

(d)

FIGURE 2: Basic parameters of analyzed studies. Relationship of BMI, age, SBP, and DBP between different disease groups and their controls. (a) BMI depicts significant differences between the control groups and their related disease groups, presenting the lowest values among the (1) control group containing healthy subjects, respectively. (b) Age presented higher results in the (1) NAFLD-NASH and the (3) DM groups than in their controls. ((c)-(d)) Both, systolic blood pressure (SBD) and diastolic blood pressure (DBP) depict an increase with the degree of NAFLD. 


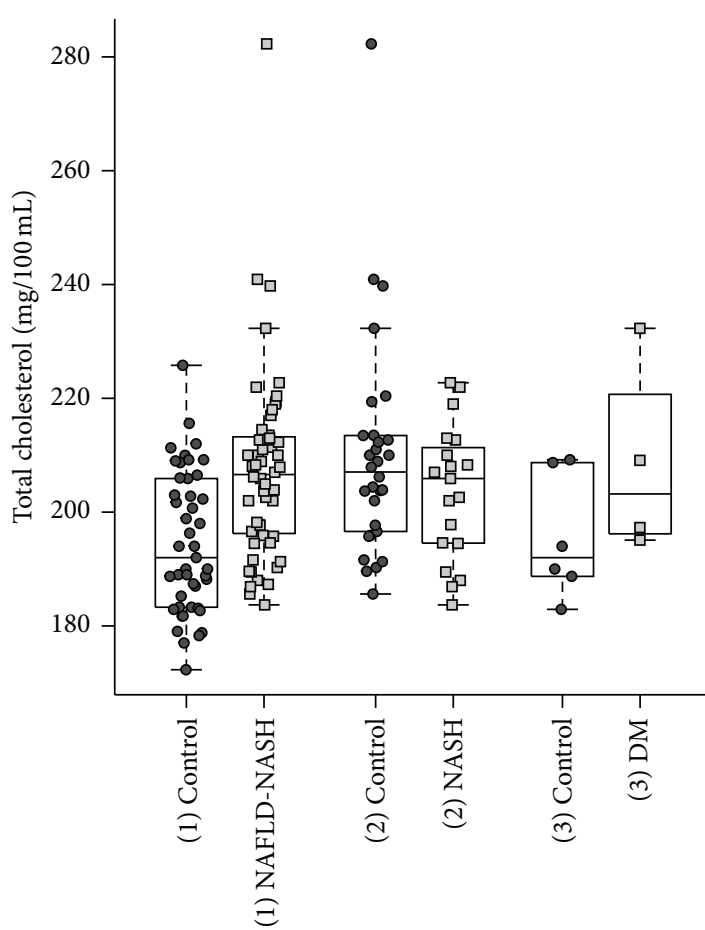

(a)

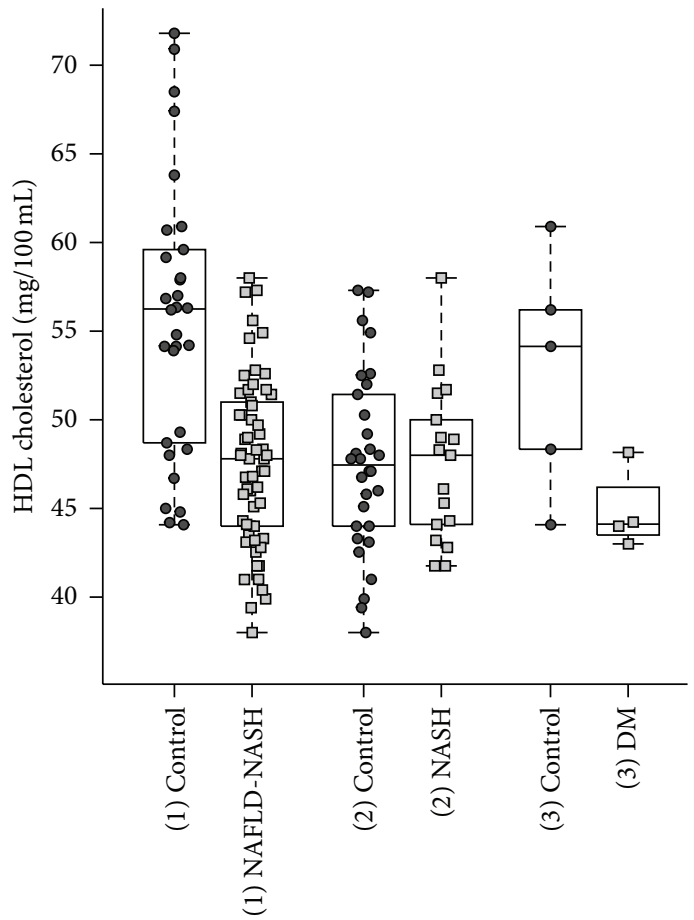

(c)

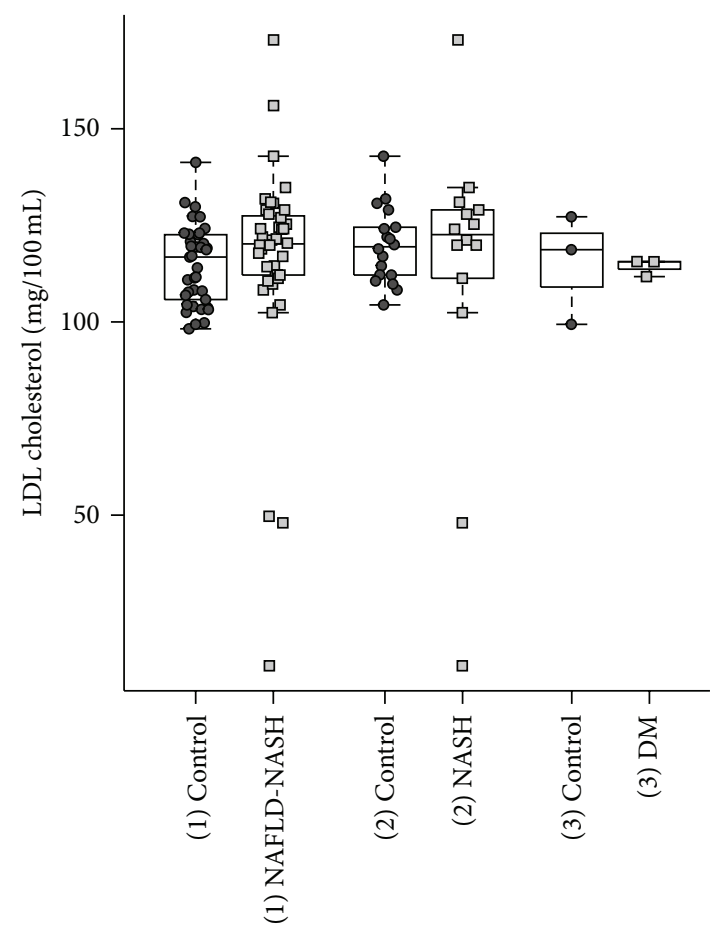

(b)

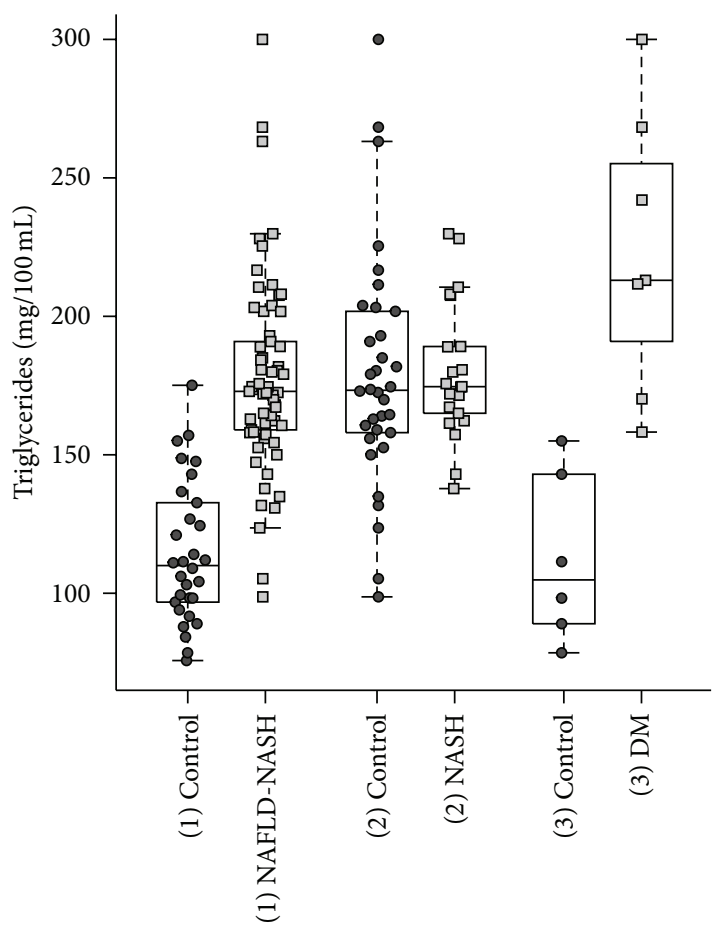

(d)

FIGURE 3: Lipid status analysis. Relationship of total cholesterol, LDL, HDL, and triglycerides between the disease groups and their controls. (a) The (1) NAFLD-NASH group presents significant higher results as its control group. (c) HDL appears higher in the (1) control group. ((a)-(d)) Merely, the triglycerides depict significant higher results in the NAFLD-NASH and the (3) DM group as compared to their controls. 


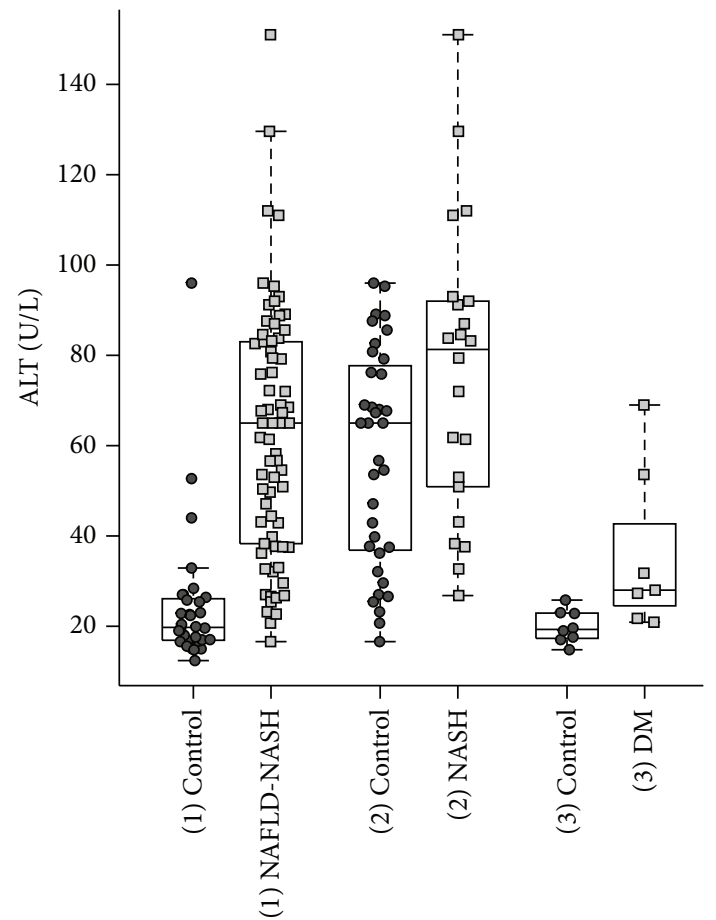

(a)

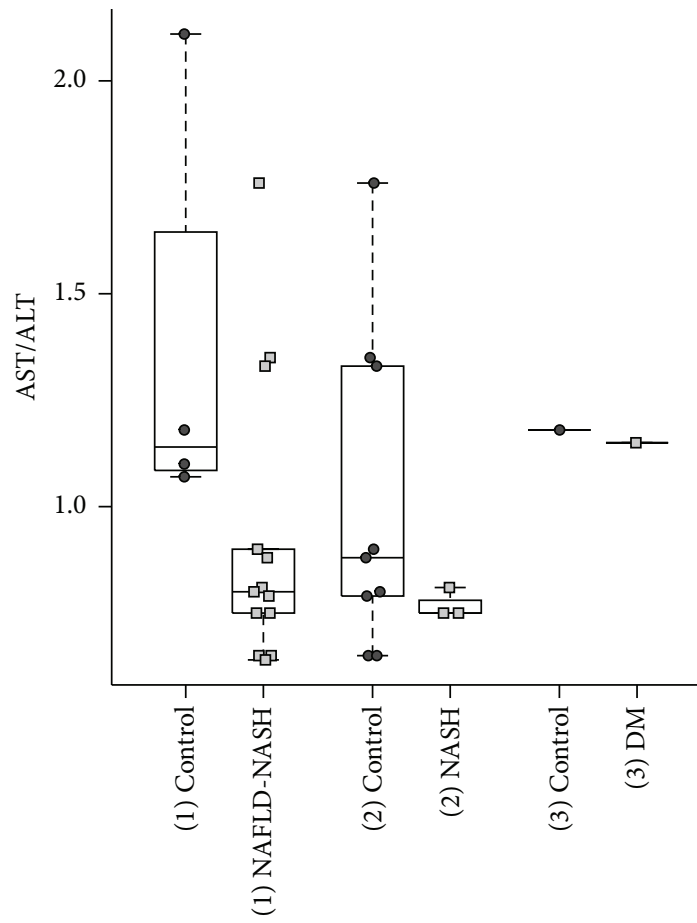

(c)

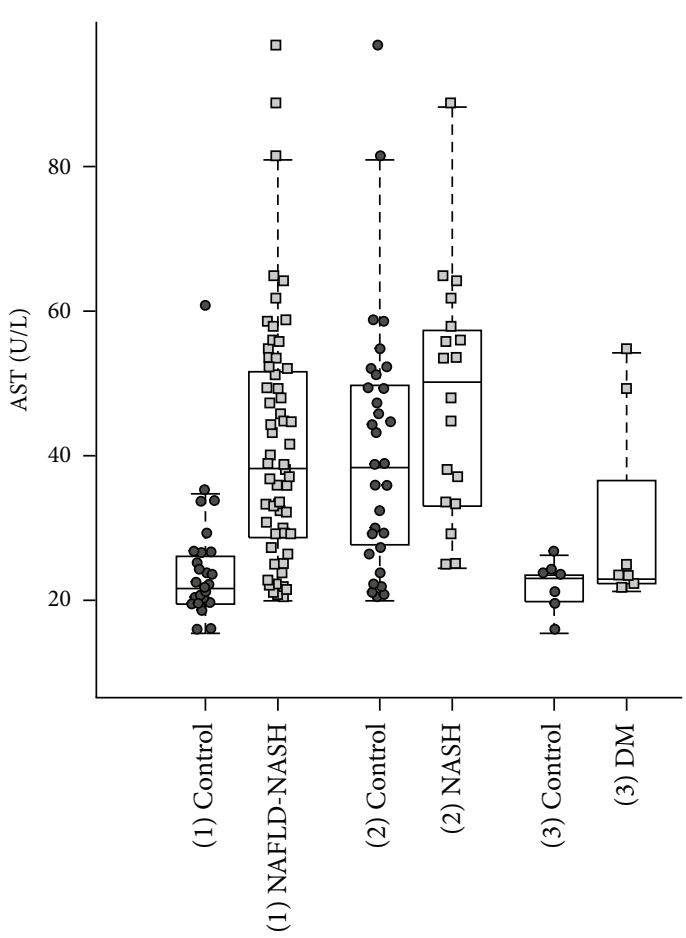

(b)

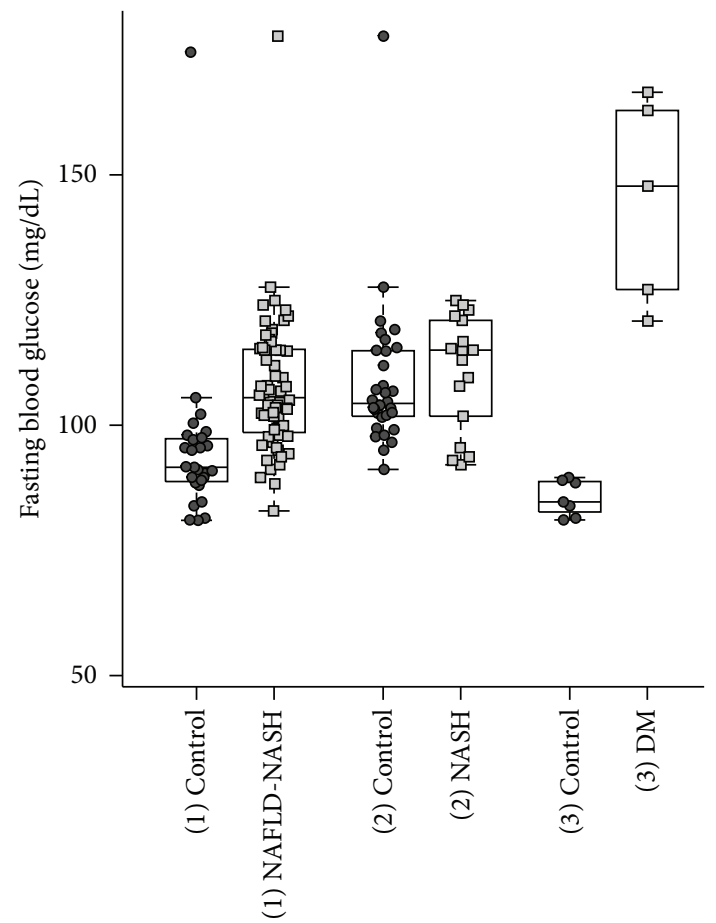

(d)

FIGURE 4: Liver enzymes analysis. Relationship of ALT, AST, AST/ALT, and fasting blood glucose (FBG) between the (1) NAFLD-NASH, the (2) NASH, the (3) DM groups, and their related control groups. ((a)-(d)) Overall, the parameters depict an increase in relation to the degree of NAFLD. 
TABLE 1: Definition of subtypes for data analysis.

(1) Control related to (1) NAFLD-NASH

(2) Control related to (2) NASH

(3) Control related to (3) DM

(4) Control related to (4) MetSy
(1) NAFLD-NASH contained healthy subjects (as defined and docusmented in the relevant studies), while the disease group consisted of NAFLD patients defined by the authors themselves.

(2) NASH comprised of NAFLD without NASH subjects, while NASH group consisted of NASH patients as defined by the authors themselves.

(3) DM consisted of subjects without diabetes, while the disease group comprised of DM patients according to the publications.

(4) MetSy-although initially considered for our statistical grouping-was omitted because of its inconsistent definition and inefficient available data.

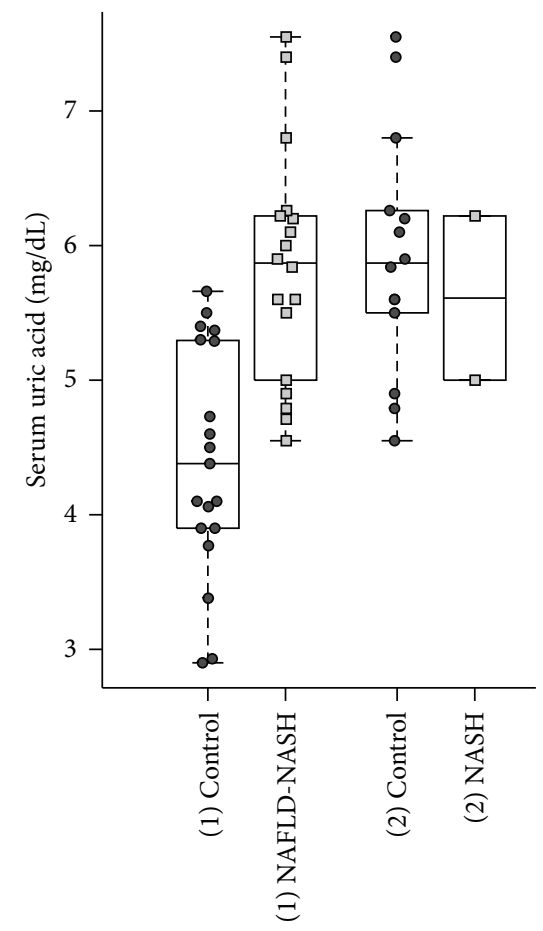

(a)

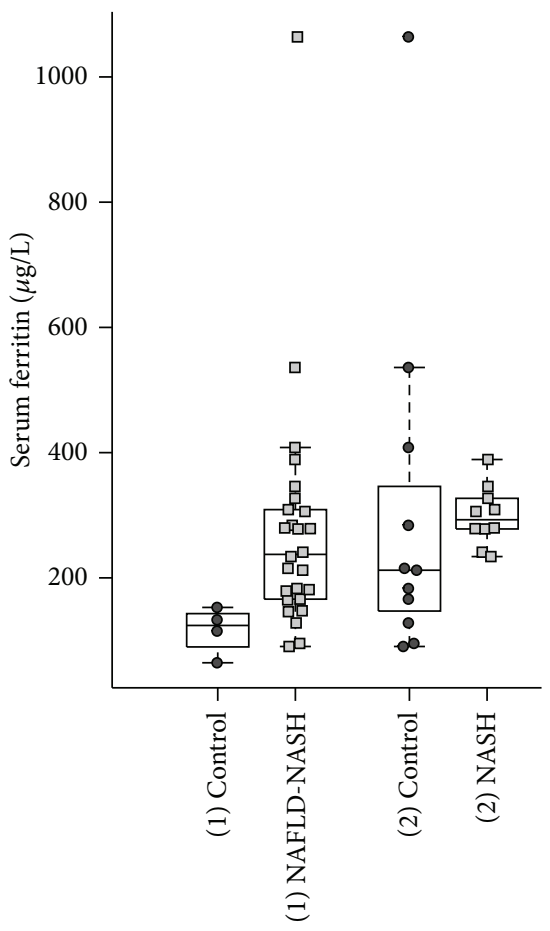

(b)

FIGURE 5: Promising parameters-potential novel biomarkers? Serum uric acid (SUA) and serum ferritin considered as potential biomarkers in the detection of NAFLD. ((a)-(b)) Both parameters illustrate significant difference between the disease groups and their controls.

The results of blood pressure depicted in the different groups demonstrated an increase of systolic (SBP) and diastolic blood pressure (DBP) with the degree of NAFLD, displaying significant differences between (1) NAFLD-NASH and the relevant $(1)$ control group $(P$ value at SBP: $1.4 \times$ $10^{-2}$ and $P$ value at DBP: $\left.4.0 \times 10^{-3}\right)$. Lipid status included total cholesterol (TC), low-density lipoprotein (LDL), highdensity lipoprotein (HDL), and triglycerides (TG) (Figure 3) displayed significant differences only between (1) NAFLDNASH group and the (1) control group ( $P$ value at TC: $2.4 \times$ $10^{-5}, P$ value at LDL: $4.0 \times 10^{-2}$, and $P$ value at HDL: $2.6 \times$ $\left.10^{-6}\right)$. Merely, triglycerides showed significantly higher levels in the (1) NAFLD-NASH group $\left(P\right.$ value: $\left.8.8 \times 10^{-12}\right)$ and in the (3) DM group $\left(P\right.$ value $\left.1.17 \times 10^{-3}\right)$ as compared to respective control groups.

We analyzed traditional liver parameters aspartate transaminase (AST), alanine aminotransferase (ALT),
AST/ALT ratio, and the Fasting Blood Glucose (FBG) (Figure 4).

Significant differences of ALT levels occurred in the (1) NAFLD-NASH group ( $P$ value: $\left.2.3 \times 10^{-11}\right)$, the $(2)$ NASH $\left(P\right.$ value: $\left.3.37 \times 10^{-2}\right)$, and the $(3) \mathrm{DM}\left(P\right.$ value: $\left.9.3 \times 10^{-3}\right)$ as compared to control groups. AST levels displayed a significant difference between (1) NAFLD-NASH group and the (1) control group $\left(P\right.$ value: $\left.1.8 \times 10^{-7}\right)$. FBG levels demonstrated significant differences in the (1) NAFLD-NASH group $(P$ value: $\left.2.6 \times 10^{-7}\right)$ and the (3) DM group $\left(P\right.$ value: $\left.2.53 \times 10^{-3}\right)$ compared to their relevant control groups.

Finally, we considered serum uric acid (SUA) and serum ferritin as potential novel biomarkers for NAFLD diagnostics (Figure 5). The (3) DM group and respective (3) control were eliminated due to inconsistent data.

Both, SUA and serum ferritin were significantly different between the (1) NAFLD-NASH and the (1) control group ( $P$ 
TABLE 2: Overview of included studies with numbers of their cohorts and size, and statistical methodology [12-30, 41-83]. Reported results were displayed in mean or median. Cohorts below 60 subjects were included due to: 1 overall many probands; 2 rare observed parameters for example, CCT, AP, insulin, ferritin, adiponectin; 3 small study because small infrastructure of this country (e.g. European studies); 4 rare documented diabetic probands of NAFLD studies.

\begin{tabular}{|c|c|c|c|c|c|}
\hline Study & $\begin{array}{l}\text { Total number of } \\
\text { included } \\
\text { cohorts of each } \\
\text { study }\end{array}$ & $\begin{array}{c}\text { Number of } \\
\text { subjects of } \\
\text { the smallest } \\
\text { included } \\
\text { cohort }\end{array}$ & $\begin{array}{l}\text { Number of } \\
\text { subjects of the } \\
\text { largest included } \\
\text { cohort }\end{array}$ & $\begin{array}{c}M=\text { Median } \\
\mathrm{A}=\text { Mean } \\
\text { MA = Mean and } \\
\text { Median mixed }\end{array}$ & $\begin{array}{c}\text { Remarks to } \\
\text { studies with } \\
\text { smaller cohorts } \\
\text { than } 60 \text { subjects }\end{array}$ \\
\hline Sun and Lü 2011 [72] & 2 & 234 & 248 & $\mathrm{~A}$ & \\
\hline Yasui et al., 2011 [71] & 2 & 82 & 92 & M & \\
\hline Lee et al., 2010 [30] & 3 & 1242 & 1276 & A & \\
\hline Xu et al., 2010 [29] & 6 & 814 & 6077 & MA & \\
\hline Hwang et al., 2011 [28] & 2 & 1613 & 3019 & $\mathrm{~A}$ & \\
\hline Arase et al., 2011 [27] & 1 & 5561 & NA & $\mathrm{A}$ & \\
\hline $\begin{array}{l}\text { Thiruvagounder et al., } 2010 \\
\text { [26] }\end{array}$ & 4 & 61 & 76 & A & \\
\hline Xu et al., $2011[25]$ & 2 & 227 & 651 & MA & \\
\hline Tan et al., 2010 [70] & 3 & 51 & 135 & A & 1 \\
\hline Caserta et al., 2010 [69] & 2 & 74 & 498 & M & \\
\hline Ferreira et al., 2010 [68] & 2 & 33 & 45 & $\mathrm{~A}$ & 2 \\
\hline Park et al., 2011 [63] & 2 & 145 & 311 & $\mathrm{~A}$ & \\
\hline Sentinelli et al., 2011 [67] & 2 & 239 & 346 & M & \\
\hline Kaelsch et al., 2011 [66] & 2 & 56 & 71 & $\mathrm{~A}$ & 1 \\
\hline de Luis et al., 2010 [21] & 2 & 15 & 68 & $\mathrm{~A}$ & 3 \\
\hline Alkhouri et al., 2010 [65] & 3 & 11 & 36 & MA & 3 \\
\hline Barchetta et al., 2011 [64] & 2 & 100 & 162 & $\mathrm{~A}$ & \\
\hline Esteghamati et al., 2010 [62] & 6 & 94 & 576 & $\mathrm{~A}$ & \\
\hline Gupta et al., 2011 [61] & 2 & 98 & 280 & MA & \\
\hline Kirovski et al., 2010 [60] & 2 & 62 & 93 & A & \\
\hline $\begin{array}{l}\text { Raszeja-Wyszomirska et al., } \\
2010[20]\end{array}$ & 2 & 14 & 48 & $\mathrm{~A}$ & 3 \\
\hline Lee et al., 2010 [59] & 2 & 24 & 25 & $\mathrm{~A}$ & 2 \\
\hline Kilciler et al., 2010 [19] & 2 & 54 & 60 & MA & 1,3 \\
\hline Abdelmalek et al., 2010 [24] & 2 & 84 & 224 & A & \\
\hline Qureshi et al., 2010 [58] & 3 & 26 & 58 & A & 2 \\
\hline Adams et al., 2010 [57] & 2 & 116 & 221 & $\mathrm{~A}$ & \\
\hline $\begin{array}{l}\text { Dongiovanni et al., } 2010 \\
\text { [56] }\end{array}$ & 2 & 202 & 346 & A & \\
\hline Harte et al., 2010 [18] & 2 & 23 & 155 & $\mathrm{~A}$ & 3 \\
\hline Younossi et al., 2011 [55] & 2 & 39 & 40 & A & 2 \\
\hline $\begin{array}{l}\text { Narciso-Schiavon et al., } \\
2010 \text { [53] }\end{array}$ & 2 & 38 & 56 & A & 2 \\
\hline Oh et al., $2011[48]$ & 10 & 39 & 358 & MA & 1,2 \\
\hline Söderberg et al., 2011 [17] & 6 & 3 & 12 & A & 3 \\
\hline Tragher 2011 & 2 & 161 & 182 & MA & \\
\hline Aigner et al., 2010 [16] & 2 & 27 & 124 & A & 3 \\
\hline $\begin{array}{l}\text { García-Monzón et al., } 2011 \\
\text { [15] }\end{array}$ & 3 & 24 & 29 & A & 3 \\
\hline $\begin{array}{l}\text { Neuschwander-Tetri et al., } \\
2010 \text { [23] }\end{array}$ & 2 & 291 & 404 & M & \\
\hline Firneisz et al., 2010 [14] & 3 & 23 & 82 & A & 3 \\
\hline Sumida et al., 2011 [51] & 2 & 198 & 244 & $\mathrm{~A}$ & \\
\hline
\end{tabular}


TABLE 2: Continued.

\begin{tabular}{|c|c|c|c|c|c|}
\hline Study & $\begin{array}{l}\text { Total number of } \\
\text { included } \\
\text { cohorts of each } \\
\text { study }\end{array}$ & $\begin{array}{l}\text { Number of } \\
\text { subjects of } \\
\text { the smallest } \\
\text { included } \\
\text { cohort }\end{array}$ & $\begin{array}{c}\text { Number of } \\
\text { subjects of the } \\
\text { largest included } \\
\text { cohort }\end{array}$ & $\begin{array}{c}M=\text { Median } \\
\mathrm{A}=\text { Mean } \\
\text { MA = Mean and } \\
\text { Median mixed }\end{array}$ & $\begin{array}{l}\text { Remarks to } \\
\text { studies with } \\
\text { smaller cohorts } \\
\text { than } 60 \text { subjects }\end{array}$ \\
\hline Eguchi et al., 2011 [50] & 3 & 74 & 375 & A & \\
\hline Ulitsky et al., 2010 [49] & 2 & 52 & 201 & $\mathrm{~A}$ & 1,2 \\
\hline Williams et al., 2011 [48] & 2 & 40 & 89 & A & 1,2 \\
\hline Sokooian S 2010 & 3 & 45 & 102 & $\mathrm{~A}$ & 1,2 \\
\hline Hotta et al., 2010 [46] & 4 & 64 & 578 & A & \\
\hline Tapan et al., 2010 [45] & 2 & 31 & 65 & MA & \\
\hline Sokooian S 2010 & 2 & 102 & 188 & A & 2 \\
\hline Aller et al., 2010 [13] & 2 & 15 & 51 & A & 3 \\
\hline $\begin{array}{l}\text { Fierbinteanu-Braticevici et } \\
\text { al., } 2011 \text { [12] }\end{array}$ & 2 & 42 & 45 & M & 3 \\
\hline $\begin{array}{l}\text { Rodriguez-Hernandez et } \\
\text { al., } 2010 \text { [43] }\end{array}$ & 4 & 29 & 229 & A & 4 \\
\hline Suzuki et al., 2010 [42] & 2 & 22 & 62 & A & 2 \\
\hline Kalhan et al., 2011 [41] & 3 & 11 & 25 & A & 2 \\
\hline Souza-Oliveira CPM 2010 & 2 & 45 & 86 & A & 2 \\
\hline Manousou et al., 2011 [22] & 4 & 24 & 64 & $\mathrm{~A}$ & 1,3 \\
\hline Park et al., 2010 [82] & 1 & 66 & NA & A & \\
\hline Sumida Y 2010 & 4 & 43 & 399 & A & 1,2 \\
\hline Tanaka et al., 2011 [74] & 1 & 55 & $\mathrm{NA}$ & M & \\
\hline Brunt et al., 2011 [80] & 3 & 183 & 543 & M & \\
\hline $\begin{array}{l}\text { Raszeja-Wyszomirska J } \\
2010\end{array}$ & 1 & 104 & NA & A & \\
\hline Baba et al., 2011 [73] & 1 & 165 & NA & A & \\
\hline Yilmaz Y 2010 & 2 & 56 & 58 & A & 1 \\
\hline Tsutsui et al., 2010 [77] & 1 & 105 & NA & A & \\
\hline Verrijken et al., 2010 [76] & 1 & 367 & $\mathrm{NA}$ & A & \\
\hline Akyildiz et al., 2010 [75] & 2 & 91 & 104 & $\mathrm{~A}$ & \\
\hline $\begin{array}{l}\text { These } 62 \text { included articles } \\
\text { contain } 45228 \text { subjects of } \\
157 \text { cohorts }\end{array}$ & & & & $\begin{array}{c}A=75,8 \% \\
M=11,3 \% \\
M A=12,8 \%\end{array}$ & \\
\hline
\end{tabular}

value at SUA: $4.6 \times 10^{-5}$ and $P$ value at serum ferritin: $6.9 \times$ $\left.10^{-3}\right)$.

4.2. Discussion. Despite of the huge amount of assessed data from 157 cohorts, our data analysis mostly revealed the already known and in clinical routine implemented results. Nonetheless, there are several remarkable results to be discussed.

First: our results demonstrated that no individual biomarkers are path-breaking, but a composition of biomarkers/biomarker grouping may be successful in clinical detection of NAFLD and its progression. Our analysis lies in (1) its scope of literature review, (2) the magnitude of cohorts included, (3) the number of parameters collected, and (4) its global approach [12-30, 41-83].

Second: overall, Europe [12-22] presented smaller cohorts than USA $[23,24]$ and Asia [25-30], due to larger population size and no geographical boundaries.
Gender and ethnicity inclusion failed because of no data.

Third: the selected parameters included standard NAFLD/NASH parameters such as liver enzymes and lipid profile. BMI and blood pressure were significantly lower in healthy control groups than in the disease group, which similarly confirmed the existing results. With respect to blood pressure, the outliers may present untreated hypertensive subjects. Furthermore, the results substantiate the theory of previous studies that the risk of NAFLD increases along with overweight and advanced age.

Differences of LDL between NAFLD subjects and their healthy control group as well as between diabetic subjects and their control group are lower than expected. In contrast, HDL levels of both the NAFLD healthy control group and the diabetic healthy control group are significantly higher as compared to their disease groups. This suggests a lower HDL level on the basis of disordered liver metabolism by NAFLD. 
Furthermore, the triglyceride level of NAFLD subjects was significantly higher than that of healthy controls. This may be the result of (a) reduced formation of VLDL and a disordered beta-oxidation, leading to lower LDL levels than expected, despite an increased triglyceride level, (b) triglyceride level of diabetic subjects is significantly higher than that of the NAFLD-NASH subjects ( $P$ value: $2.04 \times 10^{-2}$ ) and suggests the effect of insulin resistance on triglyceride metabolism by increased adipolysis.

The FBG among diabetic subjects was higher than the FBG in the NAFLD group. In contrast, AST and ALT were increased by NAFLD, but diabetic subjects presented no pathological AST and ALT elevation as the healthy group. Our data analysis of ALT, AST, and FBG showed an increase attributable to the degree of NAFLD.

Fourth: parameters such as C-reactive protein (CRP), procollagen, or hyaluronic acid may not qualify as single biomarker because of their ubiquitary presence. Serum uric acid (SUA) differed significantly between the (1) healthy control and both liver disease groups. This finding supports the theory that patients with liver disease often receive diuretics or suffer from hepatic-renal syndrome, which both may lead to reduced renal SUA elimination and increased SUA levels [31].

An association between NAFLD and SUA is most plausible explained through the "two-hit" theory, which suggests that fat accumulation in hepatocytes presents the first hit and leads to an increased vulnerability of liver. Insulin resistance plays a crucial role in this vicious circle, which promotes lipolysis of the peripheral adipose tissue and increases the influx of free fatty acids into the liver. This insulin resistance leads to hyperinsulinemia, which increases the synthesis of uric acid and decreases its renal excretion. Although high levels of uric acid were a consequence of metabolic disorders, but it does not lead direct to NAFLD [32].

Other recent studies showed that serum uric acid is independently associated with NAFLD presence and development [33].

Furthermore, a possible gender effect can influence the development and progression of NAFLD and studies showed that the incidence of NAFLD increases after menopause [34].

Ferritin results showed a significant difference between the (1) healthy control and the (1) NAFLD-NASH group. This may be explained by inflammation leading to a serum ferritin increase due to macrophages' redistribution and by liver tissue damage due to macrophages redistribution [31]. The increased serum ferritin level may serve as independent predictor of liver damage in patients with NAFLD and is useable to identify patients at risk for NASH and fibrosis [35, 36]. Recent studies suggest the possibility of utilizing serum CK-18 and ferritin levels together to distinguish NASH from NAFLD [37].

Fetuin-A, as promising novel biomarker, appeared in the literature fragmentarily [38]. Recent studies showed that mRNA, protein expression, and the serum concentration of fetuin-A were increased in NAFLD patients. The gene expression of fetuin-A seems to be coregulated with key factors in the glucose and lipid metabolism. Furthermore, the oral antidiabetic metformin was able to decrease the fetuin-A level [39].

Gamma-glutamyl transpeptidase (GGT) was found rarely documented and could not be considered. Similarly adiponectin, resistin, various interleukins (ILs) were mentioned among others. Statistical analysis was impossible since no available data or too few studies were presented.

Though the traditional parameter results did not reveal surprising findings, they confirm the impact of lifestyle [40].

\section{Conclusions}

During our search on biomarkers we noticed, between the period of April to September 2011, a doubling of publications on NAFLD/NASH from 1,500 to over 3,000 articles in PubMed. Despite these tremendous research efforts, our findings did not display clinical innovation. The results also confirmed that at this point there is no one single biomarker detecting or differentiating NAFLD. Thus, our analysis suggests coordinated, standardized scientific research and the need for a collective look at biomarker groups and their link along with lifestyle, nutrition, exercise, genetics, and other factors. This applies accordingly also in clinical research. The topic of NAFLD/NASH is so complex and interdisciplinary that there is much space for further research in NAFLD development and its process of diagnosing, treatment, and prevention. In addition, our findings suggest the necessity of harmonized data acquisition and publishing as well as data visualization in meta-analyses for an effective NAFLD biomarker identification for future clinical practicability.

\section{Abbreviations}

NAFLD: Nonalcoholic fatty liver disease

NASH: Nonalcoholic steatohepatitis

DM2: Diabetes type 2

IR: Insulin resistance

CVD: Coronary vascular disease

AFLD: Alcoholic fatty liver disease

ASH: Alcoholic fatty liver disease

MetSy: Metabolic syndrome

SD: $\quad$ Standard deviation

EDA: Exploratory data analysis

CI: Confidence interval

BMI: $\quad$ Body mass index

SBP: $\quad$ Systolic blood pressure

DBP: Diastolic blood pressure

TC: $\quad$ Total cholesterol

LDL: Low density lipoprotein

HDL: High density lipoprotein

ALT: $\quad$ Alanine transaminase

AST: Aspartate aminotransferase

FBG: $\quad$ Fasting blood glucose

MRI: Magnetic resonance imaging

HS: Hepatic steatosis

SUA: Serum uric acid

GGT: Gamma-glutamyl transpeptidase

ILs: Interleukins. 


\section{Conflict of Interests}

The authors declare that there is no conflict of interests regarding the publication of this paper.

\section{Acknowledgments}

We would like to thank all authors of all included studies for their detailed data published, which enabled us to perform the data analysis. We also acknowledge the dedicated efforts of our colleagues Ruben Charchoghlyan, Bernhard Walter Kowalski, and Gabriele Hofer at Medical University of Graz, who contributed in the data assessment. This work was supported by BioPersMed (COMET K-project 825329), which is funded by the Federal Ministry of Transport, Innovation and Technology (BMVIT) and the Federal Ministry of Economics and Labour/the Federal Ministry of Economy, Family and Youth (BMWA/BMWFJ) and the Styrian Business Promotion Agency (SFG).

\section{References}

[1] J. D. Browning, L. S. Szczepaniak, R. Dobbins et al., "Prevalence of hepatic steatosis in an urban population in the United States: impact of ethnicity," Hepatology, vol. 40, no. 6, pp. 1387-1395, 2004.

[2] L. A. Adams and K. D. Lindor, "Nonalcoholic fatty liver disease," Annals of Epidemiology, vol. 17, no. 11, pp. 863-869, 2007.

[3] E. Poggiogalle, G. Olivero, C. Anania, F. Ferraro, and L. Pacifico, "Pediatric non-alcoholic fatty liver disease: recent advances and challenges," Minerva Pediatrica, vol. 62, no. 6, pp. 569-584, 2010.

[4] H. M. Patton, C. Sirlin, C. Behling, M. Middleton, J. B. Schwimmer, and J. E. Lavine, "Pediatric nonalcoholic fatty liver disease: a critical appraisal of current data and implications for future research," Journal of Pediatric Gastroenterology and Nutrition, vol. 43, no. 4, pp. 413-427, 2006.

[5] S. E. Mahady, A. C. Webster, S. Walker, A. Sanyal, and J. George, "The role of thiazolidinediones in non-alcoholic steatohepatitis - a systematic review and meta analysis," Journal of Hepatology, vol. 55, no. 6, pp. 1383-1390, 2011.

[6] K. S. Bramlage, V. Bansal, S. A. Xanthakos, and R. Kohli, "Fatty liver disease in children-what should one do?" The Indian Journal of Pediatrics, vol. 80, no. 1, pp. 109-114, 2013.

[7] A. P. Levene and R. D. Goldin, "The epidemiology, pathogenesis and histopathology of fatty liver disease," Histopathology, vol. 61, no. 2, pp. 141-152, 2012.

[8] T. Hatta, Y. Fujinaga, M. Kadoya et al., "Accurate and simple method for quantification of hepatic fat content using magnetic resonance imaging: a prospective study in biopsy-proven nonalcoholic fatty liver disease," Journal of Gastroenterology, vol. 45, no. 12, pp. 1263-1271, 2010.

[9] Y. Sumida, Y. Eguchi, and M. Ono, "Current status and agenda in the diagnosis of nonalcoholic steatohepatitis in Japan," World Journal of Hepatology, vol. 2, no. 10, pp. 374-383, 2010.

[10] V. Ratziu, L. Martin, L. Fedchuk, and T. Poynard, "Can nonalcoholic steatohepatitis be diagnosed without liver biopsy?" Biomarkers in Medicine, vol. 3, no. 4, pp. 353-361, 2009.

[11] J. W. Tukey, Exploratory Data Analysis, Addison-Wesley Publishing Company, 1977.

[12] C. Fierbinteanu-Braticevici, C. Baicus, L. Tribus, and R. Papacocea, "Predictive factors for nonalcoholic steatohepatitis (NASH) in patients with nonalcoholic fatty liver disease (NAFLD)," Journal of Gastrointestinal and Liver Diseases, vol. 20, no. 2, pp. 153-159, 2011.

[13] R. Aller, D. A. de Luis, O. Izaola et al., “G308A polymorphism of TNF-alpha gene is associated with insulin resistance and histological changes in non alcoholic fatty liver disease patients," Annals of Hepatology, vol. 9, no. 4, pp. 439-444, 2010.

[14] G. Firneisz, T. Varga, G. Lengyel et al., "Serum dipeptidyl peptidase-4 activity in insulin resistant patients with nonalcoholic fatty liver disease: a novel liver disease biomarker," PLoS ONE, vol. 5, no. 8, Article ID e12226, 2010.

[15] C. García-Monzón, O. L. Iacono, R. Mayoral et al., "Hepatic insulin resistance is associated with increased apoptosis and fibrogenesis in nonalcoholic steatohepatitis and chronic hepatitis C," Journal of Hepatology, vol. 54, no. 1, pp. 142-152, 2011.

[16] E. Aigner, M. Strasser, H. Haufe et al., "A role for low hepatic copper concentrations in nonalcoholic fatty liver disease," American Journal of Gastroenterology, vol. 105, no. 9, pp. 19781985, 2010.

[17] C. Söderberg, J. Marmur, K. Eckes et al., "Microvesicular fat, inter cellular adhesion molecule-1 and regulatory T-lymphocytes are of importance for the inflammatory process in livers with non-alcoholic steatohepatitis," Acta Pathologica, Microbiologica et Immunologica Scandinavica, vol. 119, no. 7, pp. 412-420, 2011.

[18] A. L. Harte, N. F. Da Silva, S. J. Creely et al., "Elevated endotoxin levels in non-alcoholic fatty liver disease," Journal of Inflammation, vol. 7, article 15, 2010.

[19] G. Kilciler, H. Genc, S. Tapan et al., "Mean platelet volume and its relationship with carotid atherosclerosis in subjects with non-alcoholic fatty liver disease," Upsala Journal of Medical Sciences, vol. 115, no. 4, pp. 253-259, 2010.

[20] J. Raszeja-Wyszomirska, B. Szymanik, M. Ławniczak et al., "Validation of the BARD scoring system in Polish patients with nonalcoholic fatty liver disease (NAFLD)," BMC Gastroenterology, vol. 10, article 67, 2010.

[21] D. A. De Luis, R. Aller, O. Izaola, M. G. Sagrado, and R. Conde, "Effect of two different hypocaloric diets in transaminases and insulin resistance in nonalcoholic fatty liver disease and obese patients," Nutricion Hospitalaria, vol. 25, no. 5, pp. 730-735, 2010.

[22] P. Manousou, G. Kalambokis, F. Grillo et al., "Serum ferritin is a discriminant marker for both fibrosis and inflammation in histologically proven non-alcoholic fatty liver disease patients," Liver International, vol. 31, no. 5, pp. 730-739, 2011.

[23] B. A. Neuschwander-Tetri, J. M. Clark, N. M. Bass et al., "Clinical, laboratory and histological associations in adults with nonalcoholic fatty liver disease," Hepatology, vol. 52, no. 3, pp. 913924, 2010.

[24] M. F. Abdelmalek, A. Suzuki, C. Guy et al., "Increased fructose consumption is associated with fibrosis severity in patients with nonalcoholic fatty liver disease," Hepatology, vol. 51, no. 6, pp. 1961-1971, 2010.

[25] C. Xu, L. Xu, C. Yu, M. Miao, and Y. Li, "Association between thyroid function and nonalcoholic fatty liver disease in euthyroid elderly Chinese," Clinical Endocrinology, vol. 75, no. 2, pp. 240-246, 2011.

[26] M. Thiruvagounder, S. Khan, and D. S. Sheriff, "Non-alcoholic fatty liver disease (NAFLD) - is it an emerging risk factor for coronary artery disease? Preliminary study in a local Indian population," Sultan Qaboos University Medical Journal, vol. 10, no. 2, pp. 221-226, 2010. 
[27] Y. Arase, F. Suzuki, M. Kobayashi et al., "The development of chronic kidney disease in Japanese patients with non-alcoholic fatty liver disease," Internal Medicine, vol. 50, no. 10, pp. 10811087,2011

[28] I.-C. Hwang, S.-Y. Suh, A.-R. Suh, and H.-Y. Ahn, “The relationship between normal serum uric acid and nonalcoholic fatty liver disease," Journal of Korean Medical Science, vol. 26, no. 3, pp. 386-391, 2011.

[29] C. Xu, C. Yu, L. Xu, M. Miao, and Y. Li, "High serum uric acid increases the risk for nonalcoholic fatty liver disease: a prospective observational study," PLoS ONE, vol. 5, no. 7, Article ID el1578, 2010.

[30] J. W. Lee, Y. K. Cho, M. C. Ryan et al., "Serum uric acid as a predictor for the development of nonalcoholic fatty liver disease in apparently healthy subjects: a 5-year retrospective cohort study," Gut and Liver, vol. 4, no. 3, pp. 378-383, 2010.

[31] L. Thomas, Laboratory and Diagnosis. Indication and Evaluation/Assessment of Lab Results For Clinical Diagnosticsedition, Frankfurt/Main:TH-Books Publishing Company, 6th edition, 2005.

[32] A. S. Cardoso, N. C. Gonzaga, C. C. M. Medeiros, and D. F. de Carvalho, "Association of uric acid levels with components of metabolic syndrome and non-alcoholic fatty liver disease in overweight or obese children and adolescents," Journal De Pediatria, vol. 89, no. 4, pp. 412-418, 2013.

[33] C. Xu, C. Yu, H. Ma, L. Xu, M. Miao, and Y. Li, "Prevalence and risk factors for the development of nonalcoholic fatty liver disease in a nonobese Chinese population: the Zhejiang Zhenhai study," The Amercian Journal of Gastroenterology, vol. 108, no. 8, pp. 1299-1304, 2013.

[34] S. S. Moon, "Relationship between serum uric acid level and nonalcoholic fatty liver disease in pre- and postmenopausal women," Annals of Nutrition and Metabolism, vol. 62, no. 2, pp. 158-163, 2013.

[35] K. V. Kowdley, P. Belt, L. A. Wilson et al., "Serum ferritin is an independent predictor of histologic severity and advanced fibrosis in patients with nonalcoholic fatty liver disease," Нераtology, vol. 55, no. 1, pp. 77-85, 2012.

[36] L. Valenti, P. Dongiovanni, and S. Fargion, "Diagnostic and therapeutic implications of the association between ferritin level and severity of nonalcoholic fatty liver disease," World Journal of Gastroenterology, vol. 18, no. 29, pp. 3782-3786, 2012.

[37] Y. S. Kim, E. S. Jung, W. Hur et al., "Noninvasive predictors of nonalcoholic steatohepatitis in Korean patients with histologically proven nonalcoholic fatty liver disease," Clinical and Molecular Hepatology, vol. 19, no. 2, pp. 120-130, 2013.

[38] Y. Yilmaz, O. Yonal, R. Kurt et al., "Serum fetuin A/ $\alpha 2 \mathrm{HS}-$ glycoprotein levels in patients with non-alcoholic fatty liver disease: Relation with liver fibrosis," Annals of Clinical Biochemistry, vol. 47, no. 6, pp. 549-553, 2010.

[39] A. Kahraman, J. P. Sowa, M. Schlattjan et al., "Fetuin-A mRNA expression is elevated in NASH compared with NAFL patients," Clinical Science, vol. 125, no. 8, pp. 391-400, 2013.

[40] B. M. Attar and D. H. Van Thiel, "Current concepts and management approaches in nonalcoholic fatty liver disease," The Scientific World Journal, vol. 2013, Article ID 481893, 10 pages, 2013.

[41] S. C. Kalhan, L. Guo, J. Edmison et al., "Plasma metabolomic profile in nonalcoholic fatty liver disease," Metabolism: Clinical and Experimental, vol. 60, no. 3, pp. 404-413, 2011.

[42] K. Suzuki, H. Kirikoshi, M. Yoneda et al., "Measurement of spleen volume is useful for distinguishing between simple steatosis and early-stage non-alcoholic steatohepatitis," Нераtology Research, vol. 40, no. 7, pp. 693-700, 2010.

[43] H. Rodriguez-Hernandez, M. Cervantes-Huerta, J. L. Gonzalez, M. D. Marquez-Ramirez, M. Rodriguez-Moran, and F. Guerrero-Romero, "Nonalcoholic fatty liver disease in asymptomatic obese women," Annals of Hepatology, vol. 9, no. 2, pp. 144-149, 2010.

[44] S. Sookoian, G. O. Castaño, A. L. Burgueño, T. F. Gianotti, M. S. Rosselli, and C. J. Pirola, "The nuclear receptor PXR gene variants are associated with liver injury in nonalcoholic fatty liver disease," Pharmacogenetics and Genomics, vol. 20, no. 1, pp. $1-8,2010$.

[45] S. Tapan, T. Dogru, M. Kara et al., "Circulating levels of interleukin-18 in patients with non-alcoholic fatty liver disease," Scandinavian Journal of Clinical and Laboratory Investigation, vol. 70, no. 6, pp. 399-403, 2010.

[46] K. Hotta, M. Yoneda, H. Hyogo et al., "Association of the rs738409 polymorphism in PNPLA3 with liver damage and the development of nonalcoholic fatty liver disease," BMC Medical Genetics, vol. 11, no. 1, article 172, 2010.

[47] S. Sookoian, G. O. Castaño, A. L. Burgueño et al., "Circulating levels and hepatic expression of molecular mediators of atherosclerosis in nonalcoholic fatty liver disease," Atherosclerosis, vol. 209, no. 2, pp. 585-591, 2010.

[48] C. D. Williams, J. Stengel, M. I. Asike et al., "Prevalence of nonalcoholic fatty liver disease and nonalcoholic steatohepatitis among a largely middle-aged population utilizing ultrasound and liver biopsy: a prospective study," Gastroenterology, vol. 140, no. 1, pp. 124-131, 2011.

[49] A. Ulitsky, A. N. Ananthakrishnan, R. Komorowski et al., "A noninvasive clinical scoring model predicts risk of nonalcoholic steatohepatitis in morbidly obese patients," Obesity Surgery, vol. 20, no. 6, pp. 685-691, 2010.

[50] Y. Eguchi, T. Mizuta, Y. Sumida et al., “The pathological role of visceral fat accumulation in steatosis, inflammation, and progression of nonalcoholic fatty liver disease," Journal of Gastroenterology, vol. 46, no. 1, pp. 70-78, 2011.

[51] Y. Sumida, M. Yoneda, H. Hyogo et al., "A simple clinical scoring system using ferritin, fasting insulin, and type IV collagen $7 \mathrm{~S}$ for predicting steatohepatitis in nonalcoholic fatty liver disease," Journal of Gastroenterology, vol. 46, no. 2, pp. 257-268, 2011.

[52] G. Targher, I. Pichiri, G. Zoppini, M. Trombetta, and E. Bonora, "Increased prevalence of chronic kidney disease in patients with Type 1 diabetes and non-alcoholic fatty liver," Diabetic Medicine, vol. 29, no. 2, pp. 220-226, 2012.

[53] J. L. Narciso-Schiavon, L. L. de Schiavon, R. J. de CarvalhoFilho et al., "Clinical characteristics associated with hepatic steatosis on ultrasonography in patients with elevated alanine aminotransferase," Sao Paulo Medical Journal, vol. 128, no. 6, pp. 342-347, 2010

[54] H. J. Oh, T. H. Kim, Y. W. Sohn et al., "Association of serum alanine aminotransferase and $\gamma$-glutamyltransferase levels within the reference range with metabolic syndrome and nonalcoholic fatty liver disease," The Korean journal of hepatology, vol. 17, no. 1, pp. 27-36, 2011.

[55] Z. M. Younossi, S. Page, N. Rafiq et al., "A biomarker panel for non-alcoholic steatohepatitis (NASH) and NASH-Related fibrosis," Obesity Surgery, vol. 21, no. 4, pp. 431-439, 2011.

[56] P. Dongiovanni, R. Rametta, A. L. Fracanzani et al., "Lack of association between peroxisome proliferator-activated receptors alpha and gamma2 polymorphisms and progressive liver 
damage in patients with non-alcoholic fatty liver disease: a case control study," BMC Gastroenterology, vol. 10, article 102, 2010.

[57] L. A. Adams, S. Harmsen, J. L. St. Sauver et al., "Nonalcoholic fatty liver disease increases risk of death among patients with diabetes: a community-based cohort study," American Journal of Gastroenterology, vol. 105, no. 7, pp. 1567-1573, 2010.

[58] K. Qureshi, R. H. Clements, F. Saeed, and G. A. Abrams, "Comparative evaluation of whole body and hepatic insulin resistance using indices from oral glucose tolerance test in morbidly obese subjects with nonalcoholic fatty liver disease," Journal of Obesity, vol. 2010, Article ID 741521, 7 pages, 2010.

[59] S. H. Lee, S.-H. Jeong, Y. S. Park et al., "Serum prohepcidin levels in chronic hepatitis $\mathrm{C}$, alcoholic liver disease, and nonalcoholic fatty liver disease," The Korean journal of hepatology, vol. 16, no. 3, pp. 288-294, 2010.

[60] G. Kirovski, D. Schacherer, H. Wobser et al., "Prevalence of ultrasound-diagnosed non-alcoholic fatty liver disease in a hospital cohort and its association with anthropometric, biochemical and sonographic characteristics," International Journal of Clinical and Experimental Medicine, vol. 3, no. 3, pp. 202-210, 2010.

[61] A. C. Gupta, A. K. Chaudhory, S. Sukriti et al., "Peroxisome proliferators-activated receptor $\gamma 2$ Prol2Ala variant is associated with body mass index in non-alcoholic fatty liver disease patients," Hepatology International, vol. 5, no. 1, pp. 575-580, 2011.

[62] A. Esteghamati, A. Jamali, O. Khalilzadeh et al., "Metabolic syndrome is linked to a mild elevation in liver aminotransferases in diabetic patients with undetectable non-alcoholic fatty liver disease by ultrasound," Diabetology and Metabolic Syndrome, vol. 2, no. 1, article 65, 2010.

[63] Y. J. Park, J. H. Lim, E. R. Kwon et al., "Development and validation of a simple index system to predict nonalcoholic fatty liver disease," The Korean journal of hepatology, vol. 17, no. 1, pp. 19-26, 2011.

[64] I. Barchetta, F. Angelico, M. D. Ben et al., "Strong association between non alcoholic fatty liver disease (NAFLD) and low $25(\mathrm{OH})$ vitamin D levels in an adult population with normal serum liver enzymes," BMC Medicine, vol. 9, article 85, 2011.

[65] N. Alkhouri, T. A.-R. Tamimi, L. Yerian, R. Lopez, N. N. Zein, and A. E. Feldstein, "The inflamed liver and atherosclerosis: a Link between histologic severity of nonalcoholic fatty liver disease and increased cardiovascular risk," Digestive Diseases and Sciences, vol. 55, no. 9, pp. 2644-2650, 2010.

[66] J. Kaelsch, L. P. Bechmann, H. Kaelsch et al., "Evaluation of biomarkers of NAFLD in a cohort of morbidly obese patients," Journal of Nutrition and Metabolism, vol. 2011, Article ID 369168, 7 pages, 2011.

[67] F. Sentinelli, S. Romeo, C. Maglio et al., "Lack of effect of apolipoprotein $\mathrm{C} 3$ polymorphisms on indices of liver steatosis, lipid profile and insulin resistance in obese Southern Europeans," Lipids in Health and Disease, vol. 10, article 93, 2011.

[68] V. S. G. Ferreira, R. B. Pernambuco, E. P. Lopes et al., "Frequency and risk factors associated with non-alcoholic fatty liver disease in patients with type 2 diabetes mellitus," Arquivos Brasileiros de Endocrinologia e Metabologia, vol. 54, no. 4, pp. 362-368, 2010.

[69] C. A. Caserta, G. M. Pendino, A. Amante et al., "Cardiovascular risk factors, nonalcoholic fatty liver disease, and carotid artery intima-media thickness in an adolescent population in southern Italy," American Journal of Epidemiology, vol. 171, no. 11, pp. 1195-1202, 2010.
[70] S. Tan, L. P. Bechmann, S. Benson et al., "Apoptotic markers indicate nonalcoholic steatohepatitis in polycystic ovary syndrome," Journal of Clinical Endocrinology and Metabolism, vol. 95, no. 1, pp. 343-348, 2010.

[71] K. Yasui, Y. Sumida, Y. Mori et al., "Nonalcoholic steatohepatitis and increased risk of chronic kidney disease," Metabolism: Clinical and Experimental, vol. 60, no. 5, pp. 735-739, 2011.

[72] L. Sun and S.-Z. Lü, "Association between non-alcoholic fatty liver disease and coronary artery disease severity," Chinese Medical Journal, vol. 124, no. 6, pp. 867-872, 2011.

[73] M. Baba, K. Furuya, H. Bandou, K. Kasai, and K. Sadaoka, "Discrimination of individuals in a general population at highrisk for alcoholic and non-alcoholic fatty liver disease based on liver stiffness: a cross section study," BMC Gastroenterology, vol. 11, article 70, 2011.

[74] N. Tanaka, A. Horiuchi, T. Yokoyama et al., "Clinical characteristics of de novo nonalcoholic fatty liver disease following pancreaticoduodenectomy," Journal of Gastroenterology, vol. 46, no. 6, pp. 758-768, 2011.

[75] M. Akyildiz, F. Gunsar, D. Nart et al., "Macrophage migration inhibitory factor expression and MIF gene - 173 G/C polymorphism in nonalcoholic fatty liver disease," European Journal of Gastroenterology and Hepatology, vol. 22, no. 2, pp. 192-198, 2010.

[76] A. Verrijken, S. Francque, I. Mertens, M. Talloen, F. Peiffer, and L. Van Gaal, "Visceral adipose tissue and inflammation correlate with elevated liver tests in a cohort of overweight and obese patients," International Journal of Obesity, vol. 34, no. 5, pp. 899907, 2010.

[77] M. Tsutsui, N. Tanaka, M. Kawakubo et al., "Serum fragmented cytokeratin 18 levels reflect the histologic activity score of nonalcoholic fatty liver disease more accurately than serum alanine aminotransferase levels," Journal of Clinical Gastroenterology, vol. 44, no. 6, pp. 440-447, 2010.

[78] Y. Yilmaz, O. Yonal, R. Kurt et al., "Serum levels of osteoprotegerin in the spectrum of nonalcoholic fatty liver disease," Scandinavian Journal of Clinical and Laboratory Investigation, vol. 70, no. 8, pp. 541-546, 2010.

[79] J. Raszeja-Wyszomirska, B. Szymanik, M. Ławniczak et al., "Validation of the BARD scoring system in Polish patients with nonalcoholic fatty liver disease (NAFLD)," BMC Gastroenterology, vol. 10, article 67, 2010.

[80] E. M. Brunt, D. E. Kleiner, L. A. Wilson, P. Belt, and B. A. Neuschwander-Tetri, "Nonalcoholic fatty liver disease (NAFLD) activity score and the histopathologic diagnosis in NAFLD: Distinct clinicopathologic meanings," Hepatology, vol. 53, no. 3, pp. 810-820, 2011.

[81] Y. Sumida, Y. Yonei, K. Kanemasa et al., "Lower circulating levels of dehydroepiandrosterone, independent of insulin resistance, is an important determinant of severity of non-alcoholic steatohepatitis in Japanese patients," Hepatology Research, vol. 40, no. 9, pp. 901-910, 2010.

[82] H. Park, A. Ishigami, T. Shima et al., "Hepatic senescence marker protein-30 is involved in the progression of nonalcoholic fatty liver disease," Journal of Gastroenterology, vol. 45, no. 4, pp. 426-434, 2010.

[83] C. P. M. S. Oliveira, J. T. Stefano, A. M. Cavaleiro et al., "Association of polymorphisms of glutamate-cystein ligase and microsomal triglyceride transfer protein genes in non-alcoholic fatty liver disease," Journal of Gastroenterology and Hepatology, vol. 25 , no. 2, pp. 357-361, 2010. 


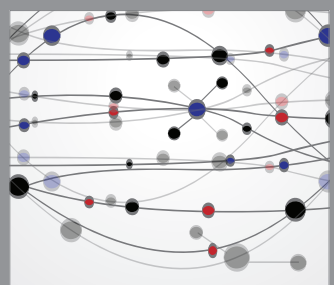

The Scientific World Journal
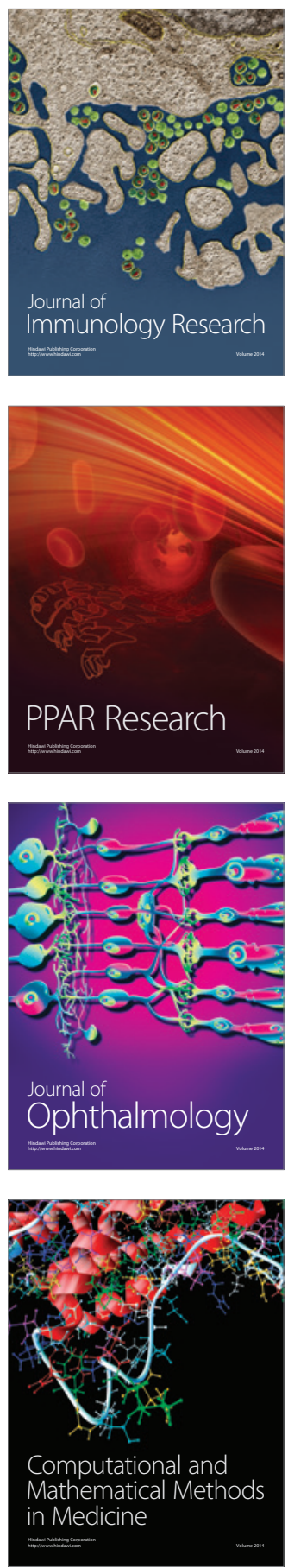

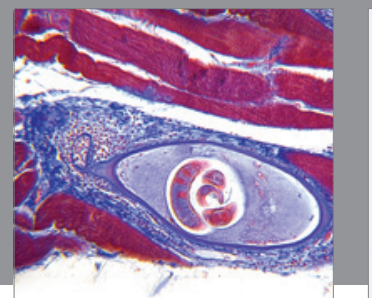

Gastroenterology

Research and Practice
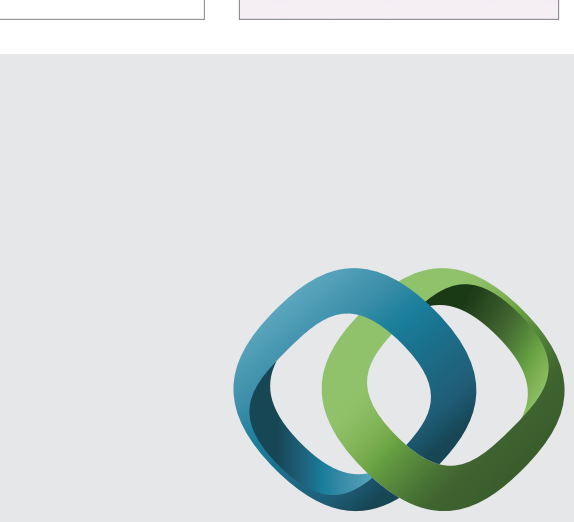

\section{Hindawi}

Submit your manuscripts at

http://www.hindawi.com
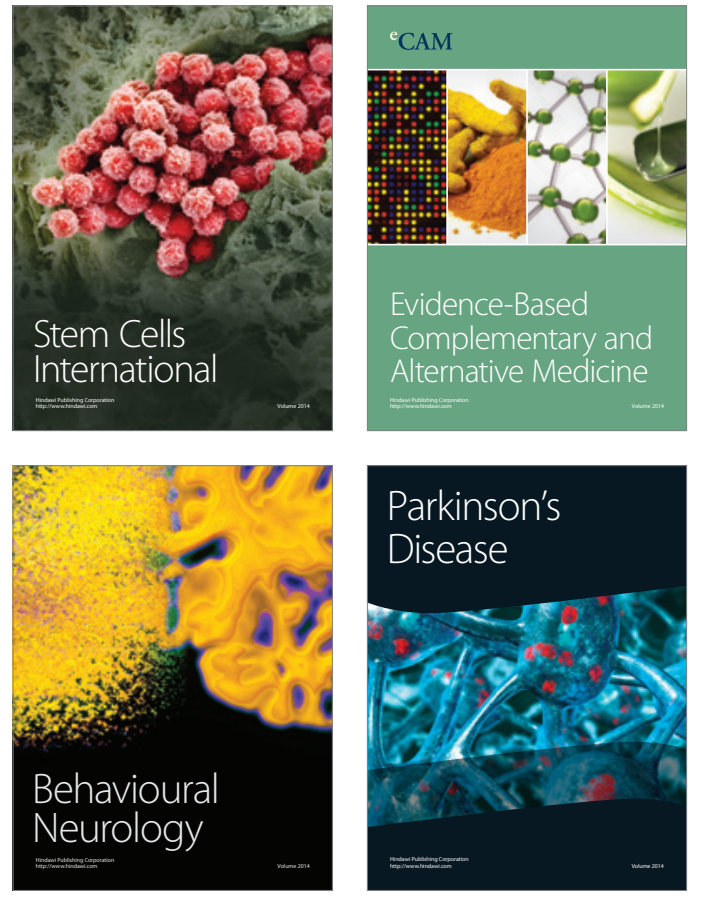
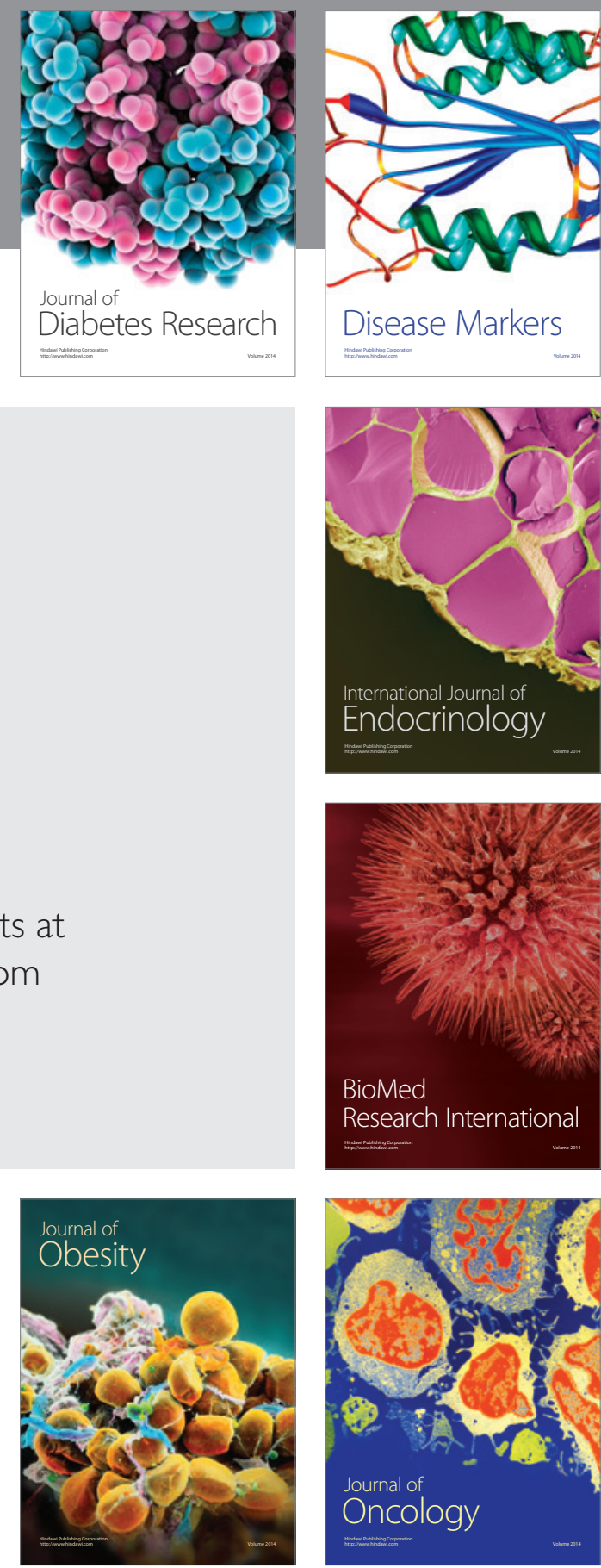

Disease Markers
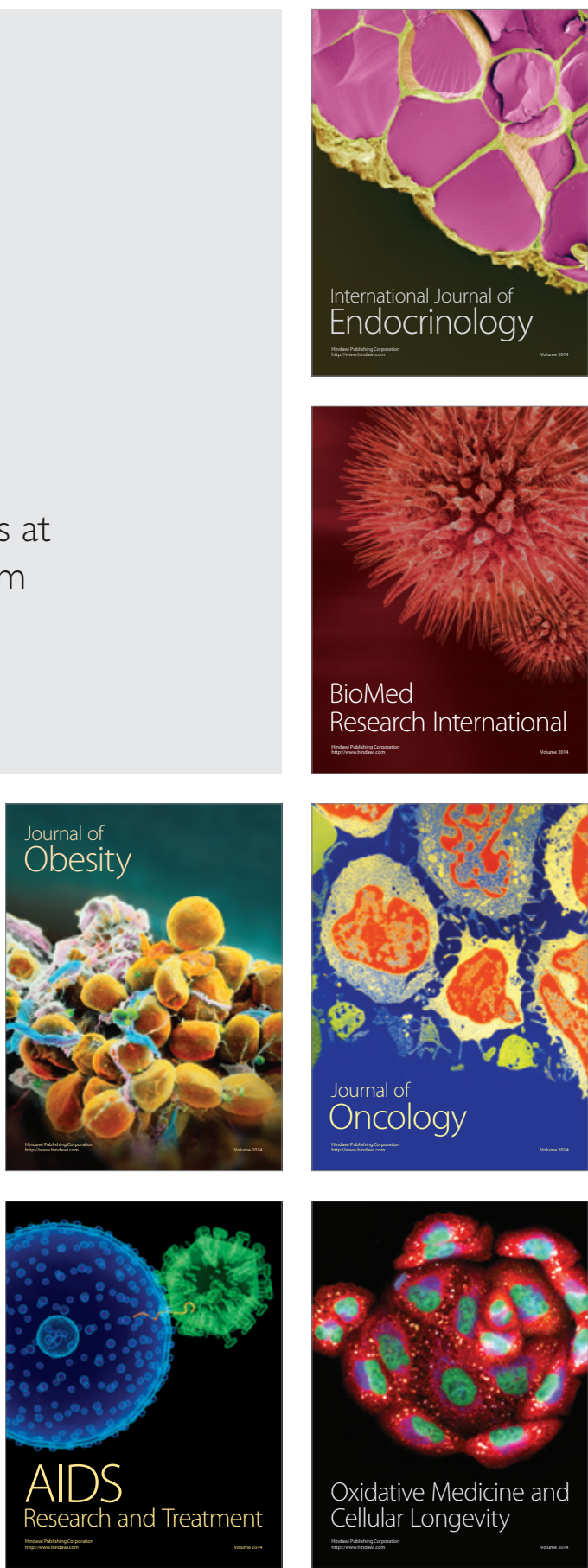